\title{
THE CASUALTY ACTUARIAL SOCIETY AND ACTUARIAL STUDIES IN DEVELOPMENT OF NON-LIFE INSURANCE IN NORTH AMERICA
}

\author{
L. H. LONGLEY-COOK, \\ Philadelphia
}
Read in his absence by Mr.F. S. Perryman to ASTIN Wednesday, 16 th October 1957

Thank you, Mr. Masterson, Sir George and friends. Mr. Masterson told you that Mr. Longley-Cook was going to give this report originally. Since he can't, he has turned it over to me, and I shall deliver it practically the way he has written it.

The profession of actuary originating in the need for a scientific approach to the problems of early life insurance companies, has broadened its scope over the years, and many actuaries now provide valuable contributions to the scientific study of problems in insurance, commerce and industry which are completely unrelated to life insurance. Because a large majority of actuaries are concerned, however, with problems of life insurance and pension plans, those outside these fields have felt the need for an association which is concerned with their special interests.

I feel most honoured to take part in the birth of AsTin, an association for the study of insurance problems outside of the life insurance field. It was most wise that Astin has been formed as a section of the International Congress and not as an independent organization because, although our problems may be different, we will gain much in our mutual association.

A specialist should not, in his devotion to his particular line of study, lose touch with the broader and more general developments of science. Cross-fertilization of ideas can, on many occasions, prove invaluable. It was over 48 years ago that Mr. Stanley Otis and others suggested that a society of actuaries and statisticians of liability companies be formed. Some five years later, the Casualty Actuarial and Statistical Society of America-later to be known 
by the shorter title of Casualty Actuarial Society-was inaugurated.

One of the first papers in the proceedings of the Society was entitled "How extensive a payroll exposure is necessary to give a dependable pure premium?" That was for Workmen's Compensation Insurance. This, the problem of the creditability of insurance data, is one of the most fundamental problems for the non-life actuary.

The Casualty Actuarial Society proceded almost at once to set up courses of study and examinations so that its members would have that broad knowledge which is so essential to the able solution up a particular problem. The Society has consistently followed this course of action, and the education work it continues to perform is as valuable today as it was in the early days.

In the first years, the problems, particularly the rate making and reserve questions relating to compensation and automobile insurance, were of predominate importance. But, as time has gone on, the Society has extended its interest to all classes of casualty insurance, and in recent years, to fire insurance.

I might interpolate here for the benefit of some of our friends from abroad. In those early days, life insurance companies in this case were divided by law into three classes: the life companies; the fire companies; and, the casualty companies. The Casualty Actuarial Society had its genesis in the casualty insurance field, but, in the last ten or a dozen years, laws have been relaxed so that non-life companies can write all classes of casualty insurance, and the Casualty Actuarial Society has extended itself to these problems or the fire field.

Continuing Mr. Longley Cook's remarks, it seems well to explain for the benefit of those of you who are unfamiliar with the practice of fire and casualty insurance in the United States of America that the industry, and particularly the rates of premium for insurance, are and have been for many years regulated by the state authorities to an extent completely unknown in most other countries. This regulation is rightly aimed at the protection of the public, and it is directed to see that insurance companies remain solvent and that premium rates are adequate, not excessive and not unfairly discriminatory.

Actuaries have had the burden of developing statistical inform- 
ation and rating plans that meet these tests, and the statistical information available in the United States of America far exceeds the comparative statistics available elsewhere.

The Proceedings of the Casualty Actuarial Society provide a fund of information on all aspects of casualty insurance and the rating techniques of retrospective and experience rating are a monument of careful study and inventiveness. In this respect-this is Mr. Longley Cook- I can praise my colleagues because I have done no work in the casualty field because since I have departed from the life field, I have been more concerned with the problems of fire insurance. That was Mr. Longley Cook. My experience was different. I left the life field and went into the casualty business and later into the fire business.

Although the scope of the Society was originally limited to casualty insurance, the broadening of the interest of the members and the introduction of many forms of multiple line policies embracing both first and third party coverage and "all risk" insurance, led to the modification of the Constitution in $195^{\circ}$ to cover all actuarial and statistical problems in insurance other than life. Prior to this time, some work had been done in fire insurance, but, because much of this was done without interchange of ideas, which a Society provides, the development in this field had been comparatively slow.

I would like to say something of the Casualty Actuarial Society as it is today. The Society has approximately 330 members of whom $\mathrm{I} 8 \mathrm{o}$ are Fellows and $\mathrm{I}_{50} \mathrm{O}$ Associates. It conducts an extensive system of examinations, one-half of which have to be passed before a candidate is admitted as an Associate. Two two-day meetings of the Society are held each year. The spring meeting is usually held in a small resort town, and the autumn meeting in a large city. These meetings provide an invaluable opportunity for the exchange of ideas and the presentation of papers.

I might emphasize this by saying that the membership of the Society is not confined to people working in companies, as I suppose the vast portion of the members are, but, there are a number of them in the independent actuarial consulting field and quite a growing number in the service of the various state governments that supervise and regulate insurance companies. Accordingly, the 
Society forms a very welcome forum for the interchange of ideas on a professional basis between people who are dealing with the same problems from different angles. It may give you some idea of the activities of the Society if I mention the papers prepared for discussion in the year 1956 .

In addition to two most stimulating addresses by our President, Mr. Masterson, we had three papers on Workmen's Compensation, one on automobile insurance and one on fire insurance. Some of you may feel as you glance through the 1956 volume of the Society's proceedings, which contain these papers, that they lack the scientific examination by mathematical study and original research. which is shown in some of the papers shown by subject IV-A of this present Congress. This is because we are practical men, engaged in practical business. In many cases, the basic theoretical studies have already been made. However, we all realize that there is much fundamental -research still to be accomplished; you can find numerous papers in our proceedings which are as concerned with fundamentals and which have the sort of mathematical approach found in those we shall be discussing this week.

It is difficult to say to what extent Astin can gain from the experience of the Casualty Actuarial Society, but it certainly can feel assured that the experience of the Casualty Actuarial Society has shown that a particular forum in which the particular problems of non-life insurance can be stated and discussed is going to help the work of all of us who are engaged in non-life insurance.

It may be desirable-this is Mr. Longley Cook again-for Astin to have yearly meetings in Europe and to set up committees on such points as standardization of terminology.

There are, of course, in many of the present societies in Europe and elsewhere opportunities for the presentation of papers not related to life insurance. But, Mr. Longley Cook concludes by saying that he believes that the formation of the present AsTin section of the International Congress will be very valuable in providing a broad forum for the discussion of non-life questions. 